\title{
EVALUATION OF INTERNAL ADAPTATION OF CLASS V RESIN COMPOSITE RESTORATIONS USING THREE TECHNIQUES OF POLYMERIZATION
}

\author{
José Carlos PEREIRA ${ }^{1}$, Paulo Henrique Perlatti D'ALPINO ${ }^{2}$, Lawrence Gonzaga LOPES ${ }^{3}$ \\ Eduardo Batista FRANCO ${ }^{4}$, Rafael Francisco Lia MONDELLI ${ }^{4}$, João Batista de SOUZA ${ }^{5}$
}

\author{
1- PhD, Chair Professor, Department of Operative Dentistry, Dental Materials and Endodontics, Bauru School of Dentistry, University of São \\ Paulo, Bauru, SP, Brazil. \\ 2- PhD, MS, Operative Dentistry, Private Practice, Bauru, SP, Brazil. \\ 3- PhD, Assistant Professor, Department of Preventive and Oral Rehabilitation, School of Dentistry, Federal University of Goiás, Goiânia, GO, \\ Brazil. \\ 4- PhD, Associate Professor, Department of Operative Dentistry, Dental Materials and Endodontics, Bauru School of Dentistry, University of \\ São Paulo, Bauru, SP, Brazil. \\ 5- PhD, Assistant Professor, Department of Preventive and Oral Rehabilitation, School of Dentistry, Federal University of Goiás, Goiânia, GO, \\ Brazil. \\ Corresponding address (Reprint requests): Prof. Dr. José Carlos Pereira - Faculdade de Odontologia de Bauru - USP - Alameda Dr. Otávio \\ Pinheiro Brizola, 9-75 - C.P. 73, Cep.: 17012-901 - Bauru, SP - phone: 551432358214 - fax: 551432348597 - e-mail: jcper@fob.usp.br \\ Received: April 20, 2006 - Modification: November 23, 2006 - Accepted: February 12, 2007
}

\begin{abstract}
O

bjective: The purpose of this in vitro study was to evaluate the internal adaptation of Class $\mathrm{V}$ composite restorations to the cavity walls using three different techniques of polymerization.

Methods: Standard cavities were prepared on the buccal and lingual surfaces of 24 extracted human third molars with margins located above and below the cementoenamel junction. Restorations were placed in one increment using two restorative systems: 3M Filtek A110/ Single Bond (M) and 3M Filtek Z250/ Single Bond (H) in the same tooth, randomly in the buccal and lingual surfaces. Resin composites were polymerized using three techniques: Group $1-$ Conventional $\left(60 \mathrm{~s}-600 \mathrm{~mW} / \mathrm{cm}^{2}\right)$; Group 2 - Soft-start (20 s- $\left.200 \mathrm{~mW} / \mathrm{cm}^{2}, 40 \mathrm{~s}-600 \mathrm{~mW} / \mathrm{cm}^{2}\right)$; Group 3 - Pulse Activation (3 s - $200 \mathrm{~mW} / \mathrm{cm}^{2}$, 3-min hiatus, 57 $\left.\mathrm{s}-600 \mathrm{~mW} / \mathrm{cm}^{2}\right)$. Buccolingual sections were polished, impressions taken and replicated. Specimens were assessed under scanning electron microscopy up to X1000 magnification. Scores were given for presence or absence of gaps $(0-$ no gap; $1-$ gap in one wall; 2 - gap in two walls; 3 - gap in three walls).

Results: The mean scores of the groups were ( \pm SD) were: G1M-3.0 ( \pm 0.0$)$; G2M-2.43 ( \pm 0.8$)$; G3M- $1.71( \pm 0.9)$; G1H- $2.14( \pm$ 1.2); G2H- 2.00 ( \pm 0.8$)$; G3H- 1.67 ( \pm 1.1$)$. Data were analyzed using Kruskal-Wallis and Dunnet's tests. No statistically significant difference $(\mathrm{p}>0.05)$ was found among groups. Gaps were observed in all groups.

Conclusions: The photocuring technique and the type of resin composite had no influence on the internal adaptation of the material to the cavity walls. A positive effect was observed when the slow polymerization techniques were used.
\end{abstract}

Uniterms: Dental materials; Polymerization shrinkage; Composite resins; Light-curing.

\section{INTRODUCTION}

The main problem faced by clinicians when restoring Class V or cervical cavities with resin composites is how to deal with the marginal quality of the restoration. The most relevant factors related to this are polymerization shrinkage, adhesion to the cavity walls, viscosity and stiffness of composite, and flexibility of the cavity walls ${ }^{9,19}$. The shrinkage, which follows the setting of resin-based materials, leads to marginal gap formation (10-15 mm). This gap often remains open, despite expansion of the restoration following water absorption ${ }^{23}$. Polymerization shrinkage is a complex process depending on several factors. The volumetric contraction causes debonding forces at the material/tooth interface ${ }^{11}$. Conventional polymerization technique immediately provides the maximal light intensity causing the hardening of the resin composite in a few seconds, severely limiting its flow ${ }^{13}$. The reactive heat leads to a further increase in the speed of polymerization creating the gel effect, which produces a considerable increase in the viscosity of composite materials ${ }^{25}$. A fast and intense polymerization leads to an excessive parietal stress, which is absorbed 
without creating marginal fractures only if properly compensated by the elastic behavior of the material or tooth ${ }^{6}$. A high degree of conversion, which is primarily related to curing light intensity and exposure time, is an important factor for the longevity of a restoration ${ }^{7}$. The greater the conversion, the higher the polymerization rate; the more the resin cures, the more it shrinks 22 .

The stress resulting from this shrinkage has been associated with open margins between the restoration and the tooth, overt tooth straining or fracture, and postoperative sensitivity ${ }^{1,3,4}$. Adhesive failure can also occur at the internal interface, leading to the formation of internal gaps between the material and the dentin surface ${ }^{10,18}$. Such openings or gaps are considered deleterious because they allow the transit of fluid or materials between the dentinpulp complex and the oral environment ${ }^{2}$. Some studies have recently shown that a controlled polymerization of resin composites using pre-polymerization at a low light intensity followed by a final cure at a high light intensity may result in improved marginal integrity without jeopardizing the achievable material properties ${ }^{5,11,17,24}$. The results obtained by Mehl, et al. ${ }^{17}$ (1997) indicate that initial cure with lower light intensity followed by final cure with high light intensity has no influence on microhardness and increases flexural modulus and flexural strength. Other studies have stated, however, that this procedure leads to worsened material properties resulting in a lower resistance to wear and fracture $^{20}$.

Low intensity curing technique is accomplished by different ways. The so-called "soft-start polymerization technique", due to its initial low light intensity, increases the resin composite flow capability before reaching the gel stage in response to an extended curing time $\operatorname{span}^{21}$. Afterwards, high light intensity is necessary to ensure complete polymerization and optimal mechanical properties ${ }^{13}$. It has been pointed out that soft-start polymerization techniques improved the marginal adaptation of Class V composite resin restorations ${ }^{19}$. It has also been found that the marginal adaptation of all restorations with enamel or dentin margins was not improved with soft-start techniques, compared to the use of conventional polymerization ${ }^{11}$. Kanca and $\operatorname{Suh}^{16}$ (1999) developed the "pulse polymerization technique" using a low-intensity (around $200 \mathrm{~mW} / \mathrm{cm}^{2}$ ) short time exposure (2-3 seconds), followed by a longer application (10-20 seconds) at higher intensity $\left(600 \mathrm{~mW} / \mathrm{cm}^{2}\right)$ after a hiatus of 3-5 minutes. Such method does not seem to modify the polymerization mechanisms and the degree of conversion of the monomer? The pulse activation technique reduces the amount of contraction stress on the margins of the restoration and, at the same time, is convenient and time-efficient ${ }^{15}$.

The purpose of this in vitro study was to evaluate the influence of the polymerization techniques on the internal adaptation of class $\mathrm{V}$ resin composite restorations.

\section{MATERIALAND METHODS}

In order to evaluate the influence of the polymerization technique on the internal adaptation of resin composite restorations, in vitro standard Class $\mathrm{V}$ cavities were prepared on the buccal and lingual surfaces of 30 human extracted third molars. The teeth were stored in $0.5 \%$ chloramine $\mathrm{T}$ at $4^{\circ} \mathrm{C}$ and used within one month following extraction. The cavities were prepared using a diamond bur (\#2136, K.G. Sorensen, São Paulo, Brazil) at high speed with a water coolant. Cavity dimensions (2.0 mm deep x $4.0 \mathrm{~mm}$ wide x 3.0 $\mathrm{mm}$ long) were standardized using a digital caliper (Model CD-6BS; Mitutoyo, Tokyo, Japan). Cavity margins were located above and below the cementoenamel junction. Two commercial brands of resin composites (Table 1) were used to restore the cavities and were inserted in one increment (bulk technique). The materials were applied in the same tooth, randomly on the buccal or lingual surfaces using the same dentin-bonding system (Single Bond; 3M ESPE, St. Paul, MN, USA), according to manufacturer's instructions, in both sides. Demetron curing light (Optilux 500, Kerr, Orange, CA, USA) with a dimmer for low intensity lights was the unit used at $600 \mathrm{~mW} / \mathrm{cm}^{2}$, monitored by a hand-held radiometer. The light exposure time was also controlled. The light tip was placed closer, but not touching, the specimens' surface. Table 2 presents the experimental groups according to the variables considered.

After the restorative procedures, the specimens were

TABLE 1- Tested materials

Product $\quad 3 M^{\varepsilon}$ Filtek A110 (M) $\quad 3 M^{\varepsilon}$ Filtek Z250 (H) $\quad 3 M^{\varepsilon}$ Single Bond

Description Microfilled resin composite

Composition

TEGDMA, UDMA and Bis-EMA.

Particle size distribution

$0.01-0.09 \mu \mathrm{m}$

(average $0.04 \mu \mathrm{m}$ )
Hybrid resin composite

BIS-GMA and TEGDMA.

Particle size distribution

0.01 to $3.5 \mu \mathrm{m}$

(average $0.6 \mu \mathrm{m}$ )
Adhesive system

Solution of water,

ethanol, HEMA, BisGMA,

dimethacrylate and

methacrylate functional

copolymer of acids

£3M Dental Products, St. Paul MN, USA 
stored in distilled water at $37^{\circ} \mathrm{C}$ during one week. After that, the restorations were finished using sequential aluminum oxide discs (SofLex Pop-On Polishing disks, 3M ESPE, St. Paul, MN, USA). The teeth were then sectioned buccolingually through the middle of the restoration using a diamond disc (Isomet, Buehler Ltd., Evanston, IL, USA) at $300 \mathrm{rpm}$, under water cooling. The sections were sequentially polished with a 600 - and a 1,200-grit silicon carbide paper. In order to remove the smear layer, the sections were cleaned with $10 \% \mathrm{H}_{3} \mathrm{PO}_{4}$ gel (All-Etch, Bisco, Inc., Schaumburg, IL, USA) for $30 \mathrm{~s}$ and then rinsed with an air-water spray for 30 s. After been slightly air-dried, impressions of the cut surfaces were taken using a vinyl polysiloxane impression material (Aquasil ULV, Dentsply De Trey, Konstanz, Germany). Replicas were made with self-curing epoxy resin (Araldite DRL and Hardener, Ciba Geigy), reproducing the interface between dental tissues and restorative material. These resin replicas were then mounted on custom-made aluminum stubs, gold-sputtered and examined with a scanning electron microscope (JEOL JSM- T220 A, JEOL Ltd., Tokyo, Japan) at magnifications of up to X1000. Photographs were taken of the occlusal, axial and gingival restoration interfaces. Scores were given to each specimen regarding the presence or absence of gaps as follows: 0 no gap; 1 - gap in one wall; 2 - gap in two walls; 3 - gap in three walls.

Data were analyzed statistically by Kruskal-Wallis nonparametric test. Dunnet's test was used as a multiple comparison test at a pre-set alpha of 0.05 .

\section{RESULTS}

The scores for internal adaptation of resin composite restorations to the cavity walls are shown on Table 3 and illustrate the influence of light intensity. The results show that irrespective of the properties of the resin composite and the technique of polymerization, there was no group free of gaps. Even though the groups G1M and G1H presented the highest scores, no significant difference among these and other groups was found $(\mathrm{p}<0.05)$. Comparisons between microfilled and hybrid scores were analyzed and no significant difference was observed as well $(p<0.05)$. However, a positive effect related to the lowering of the initial light curing intensity can be observed in the groups $\mathrm{G} 3 \mathrm{M}$ and $\mathrm{G} 3 \mathrm{H}(\mathrm{p}>0.05)$. Both groups showed the lowest scores.

Figures 1 and 2 are SEM photomicrographs showing the morphologic analysis of resin composite's internal adaptation. The most common finding was the presence of gaps in most specimens. All specimens of the group restored with microfilled composite and polymerized with the conventional technique (G1M) presented gaps in all walls. Figure 1 shows an example of gap observed in this group. Perfect margins, more frequently observed in groups 2 and 3 , are presented in the Figure 2.

\section{DISCUSSION}

Polymerization stresses developed at the adhesive interface play an important role on the marginal adaptation of resin composite restorations. Contraction stress values can exceed the bond strength, leading to the formation of openings and gaps. They are considered deleterious because they allow the transfer of fluid between the oral environment and the pulp, through the dentin tubules. The rate at which the polymerization occurs is the main factor related to the tensile forces along the tooth/restoration interface. Cavity configuration and flexural modulus of the restorative materials are other factors involved in this process. The highest $\mathrm{C}$-factors are accompanied by

TABLE 3- Score means of the gaps at the adhesive interface of class $V$ cavities restored with microfilled and hybrid resin composites

\begin{tabular}{ll}
\hline Group & Score means \pm SD \\
\hline$G 1 M$ & $3.00 \mathrm{a} \pm 0.0$ \\
$G 2 M$ & $2.43 \mathrm{a} \pm 0.787$ \\
$G 3 M$ & $1.71 \mathrm{a} \pm 0.951$ \\
$G 1 H$ & $2.14 \mathrm{a} \pm 1.215$ \\
$G 2 H$ & $2.00 \mathrm{a} \pm 0.816$ \\
$G 3 H$ & $1.67 \mathrm{a} \pm 1.033$ \\
\hline
\end{tabular}

Different letters indicate statistically significant difference at $5 \%$.

TABLE 2- Studied groups according to the variables considered

\begin{tabular}{lll}
\hline Groups & Polymerization technique & Time and intensities \\
\hline Group 1 & Conventional & $60 \mathrm{~s}-600 \mathrm{~mW} / \mathrm{cm}^{2}$ \\
Group 2 & Soft-start & $20 \mathrm{~s}-200 \mathrm{~mW} / \mathrm{cm}^{2} ;$ \\
& & $40 \mathrm{~s}-600 \mathrm{~mW} / \mathrm{cm}^{2}$ \\
Group 3 & Pulse activation & $3 \mathrm{~s}-200 \mathrm{~mW} / \mathrm{cm}^{2} ;$ \\
& & $3-\mathrm{min}$. hiatus; \\
& & $57 \mathrm{~s}-600 \mathrm{~mW} / \mathrm{cm}^{2}$ \\
\hline
\end{tabular}


increasing internal stresses with the use of resin composite restorations ${ }^{4}$. The Class $\mathrm{V}$ cavities prepared in this study, with a $\mathrm{C}$-factor of 3.3, were purposely selected, being associated with high internal contraction stresses. The combination of a resin composite with different flexural modulus and a cavity with a high $\mathrm{C}$-factor means a great challenge to the tooth-restorative interface. In addition to the resin, bulk increment application technique adds an extra tensile force, maximizing the stressing of materials. The modulus of elasticity also affects stress development in resin composite restorations. The polymerization of materials with higher modulus results in greater setting stresses than in materials with lower modulus. In this study, two materials with different modulus were randomly applied to the same substrate, on the buccal and lingual surfaces of the same tooth. 3M Filtek Z250 presents a modulus of elasticity around 11,000 MPa and 3M Filtek A110 around 6,000 MPa (technical information). In spite of the great discrepancy between these values, in the present study, there was no significant difference between the microfilled and hybrid composites with respect to marginal quality.

A variety of polymerization techniques has been tried to determine which one could provide a better internal adaptation $^{21}$. It is believed that the resin increments closest to the light source receive the highest power and energy densities. The maximal light intensity provided by conventional light-activating units rapidly increases the viscosity of resin composite, severely limiting its flow. A fast and intense polymerization leads to an excessive stress, which is not absorbed, creating marginal fracture ${ }^{19}$. Therefore, it would be highly desirable to use techniques that would produce a minimal amount of tension at the cavosurface interface. The results of this study showed that the highest values of marginal failure were found when the conventional light-curing technique was applied. The specimens of group G1M presented the highest scores. This might have occurred because of the high resin content of the microfilled resin composite, presenting high polymerization shrinkage. Thus, the consequence was the presence of gaps in all cavity walls. Specimens from group

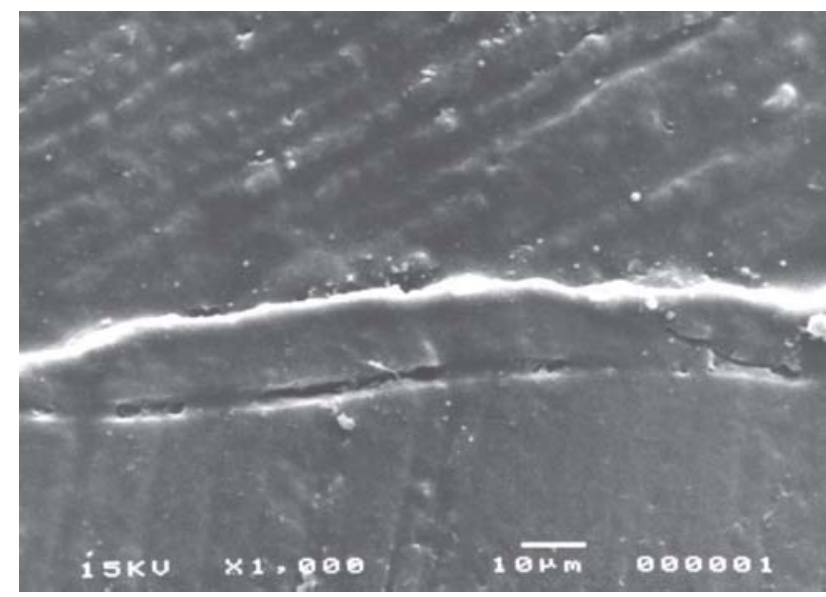

FIGURE 1- Conventional polymerization/microfilled resin composite. Presence of gaps at the axial wall
G1H presented the highest values of the groups restored with hybrid resin composite, but lower than those of G1M. Gaps found at the tooth/restoration interface of the groups restored with microfilled composite were more evident and larger than those seen in groups restored with hybrid resin composite.

One method to reduce the polymerization stress is to allow flow to occur in the resin during setting by means of controlled polymerization. Many studies have shown that this procedure may result in a smaller marginal gap and increased marginal integrity ${ }^{12,13,24}$. The method of slow polymerization, proposed in $1991^{24}$, has largely been adopted and aims to lengthen the early setting phase, so that polymerization shrinkage takes place when the molecules still have the possibility of taking a new direction to compensate for internal stress. Thus, the contraction stress developed during the final setting is decreased ${ }^{13}$. This polymerization technique was tested to evaluate its efficacy in preventing gap formation through stress relief. However, groups $\mathrm{G} 2 \mathrm{M}$ and $\mathrm{G} 2 \mathrm{H}$ presented intermediate values compared to the other groups and there was no statistically significance difference between them and the groups restored with the conventional techniques. The findings of this study corroborate data presented by Yap, et al..$^{27}$ (2001), who found that, even though the effectiveness of cure was not significantly affected by soft-start polymerization, there was no significant reduction in polymerization shrinkage with use of this polymerization system.

The pulse technique utilizes a low-level intensity for a specific network formation at the top surface, and allows the curing process to proceed more slowly in the depth underneath $^{21,26}$. This setting is normally used for the last increment at the cavosurface margin. In this study the resin composite was applied in one increment. The surface of the composite is considered properly cured following the protocol of application of $200 \mathrm{~mW} / \mathrm{cm}^{2}$ for $3 \mathrm{~s}$ followed by a 3 -min hiatus time. Then, deeper curing levels at $600 \mathrm{~mW} /$ $\mathrm{cm}^{2}$ were carried out for $57 \mathrm{~s}$.

Results in this study showed that the marginal adaptation of restorations was not significantly superior using pulse

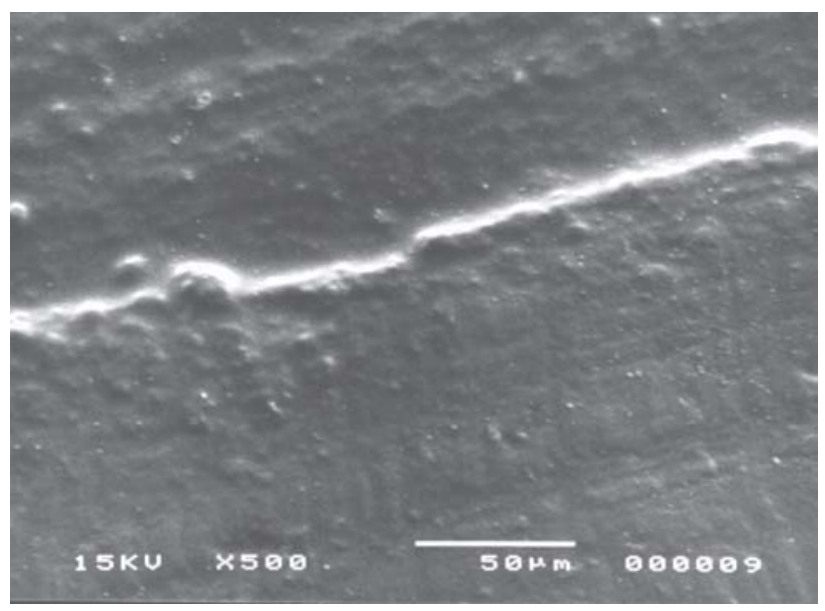

FIGURE 2- Soft start-polymerization technique/hybrid resin composite. Absence of gaps at the axial wall, showing perfect margins 
activation compared with conventional polymerization and soft-start polymerization. On the other hand, slowing down the rate of polymerization technique (pulse activation) produced the lowest values. Thus, a positive effect influencing the marginal quality of internal adaptation of the restoration was observed with the use of soft start polymerization and pulse activation methods, decreasing the scores as the initial light intensity also decreased. The pulse activation technique presented the lowest means and microfilled and hybrid resin composite presented similar scores. Mehl, et al. ${ }^{17}$ (1997) mentioned that this effect was strongly related to the initial curing intensity and to the relationship between initial and final curing intensity. In the same way, Witzel, et al. ${ }^{26}$ (2005) demonstrated that the pulse activation reduces the amount of contraction stress on the margins of the restoration. Table 3 summarizes the results and confirms these statements.

The results of the present study indicate that applying low intensity lights may have resulted in no significant effects. At first, results seemed to be contradictory to the findings of Goracci, et al..$^{13}$ (1995) and Kanca and $\operatorname{Suh}^{16}$ (1999), who pointed out that soft-start and pulse activation polymerization methods, respectively, improved the adaptation of composite resin restorations. One reason for this fact might be the very high level of photo-initiators in the resin composite materials evaluated. Ernst, et al. ${ }^{8}$ (2000) argued that, even at a low intensity level, the materials reach their maximum elasticity within a few seconds after the start of the curing procedure. Another explanation is that the gaps were evaluated according to their presence or absence, irrespective of their width or length. Clinically, stresses may also be generated at the interface during tooth function. These stresses are even more critical in Class V restorations because they may undergo flexure along with the tooth during mastication ${ }^{14}$. Thermal or mechanical stress concentration may lead to deterioration of preexisting gaps or formation of new ones. It is believed that the presence of gaps, irrespectively of their extension, turns against the lifespan of the restoration.

\section{CONCLUSIONS}

Based on the limitations of this study, it may be concluded that the internal adaptation of Class $\mathrm{V}$ resin composite restorations were influenced neither by the photoactivation technique (conventional, soft-start or pulse technique), nor by the type of resin composite (microfilled or hybrid composites).

\section{REFERENCES}

1- Abbas G, Fleming GJ, Harrington E, Shortall AC, Burke FJ. Cuspal movement and microleakage in premolar teeth restored with a packable composite cured in bulk or in increments. J Dent. 2003;31(6):437-44
2- Amaral CM, Peris AR, Ambrosano GM, Pimenta LA. Microleakage and gap formation of resin composite restorations polymerized with different techniques. Am J Dent. 2004;17(3):156-60.

3- Braga RR, Ferracane JL. Alternatives in polymerization contraction stress management. Crit Rev Oral Biol Med. 2004;15(3):176-84.

4- Carvalho RM, Pereira JC, Yoshiyama M, Pashley DH. A review of polymerization contraction: the influence of stress development versus stress relief. Oper Dent. 1996;21(1):17-24.

5- Cavalcante LM, Peris AR, Amaral CM, Ambrosano GM, Pimenta LA. Influence of polymerization technique on microleakage and microhardness of resin composite restorations. Oper Dent. 2003;28(2):200-6.

6- Davidson CL, Gee AJ. Light-curing units, polymerization, and clinical implications. J Adhes Dent. 2000;2(3):167-73.

7- Emami N, Soderholm KJ, Berglund LA. Effect of light power density variations on bulk curing properties of dental composites. J Dent. 2003;31(3):189-96.

8- Ernst CP, Kurschner R, Rippin G, Willershausen B. Stress reduction in resin-based composites cured with a two-step light-curing unit. Am J Dent. 2000;13(2):69-72.

9- Feilzer AJ, Gee AJ, Davidson CL. Setting stress in composite resin in relation to configuration of the restoration. J Dent Res. 1987;66(11):1636-9.

10- Ferrari M, Tay FR. Technique sensitivity in bonding to vital, acid-etched dentin. Oper Dent. 2003;28(1):3-8.

11- Friedl KH, Schmalz G, Hiller KA, Markl A. Marginal adaptation of Class V restorations with and without "softstart-polymerization". Oper Dent. 2000;25(1):26-32.

12- Goracci G, Mori G, Bazzucchi M. Marginal seal and biocompatibility of a fourth-generation bonding agent. Dent Mater. $1995 ; 11(6): 343-7$

13- Goracci G, Mori G, Bazzucchi M, Casa de'Martinis L. Dentinal adhesive with composite restorations: a clinical and microstructural evaluation. Int J Prosthodont. 1995;8(6):548-56.

14- Hakimeh S, Vaidyanathan J, Houpt ML, Vaidyanathan TK, Von Hagen S. Microleakage of compomer class V restorations: effect of load cycling, thermal cycling, and cavity shape differences. J Prosthet Dent. 2000;83(2):194-203.

15- Kanca J. Clinical experience with PYRAMID stratified aggregate restorative and the VIP unit. Compend Contin Educ Dent. 1999;(25):S67-72

16- Kanca J, Suh BI. Pulse activation: reducing resin-based composite contraction stresses at the enamel cavosurface margins. Am J Dent. 1999;12(3):107-12.

17- Mehl A, Hickel R, Kunzelmann KH. Physical properties and gap formation of light-cured composites with and without 'softstartpolymerization'. J Dent. 1997;25(3-4):321-30.

18- Pashley DH, Pashley EL, Carvalho RM, Tay FR. The effects of dentin permeability on restorative dentistry. Dent Clin North Am. 2002;46(2):211-45.

19- Peutzfeldt A, Asmussen E. Determinants of in vitro gap formation of resin composites. J Dent. 2004;32(2):109-15.

20- Peutzfeldt A, Asmussen E. Modulus of resilience as predictor for clinical wear of restorative resins. Dent Mater. 1992;8(3):146-8. 
21- Rueggeberg F. Contemporary issues in photocuring. Compend Contin Educ Dent. 1999;25:S4-S15.

22- Ruyter IE. Monomer systems and photopolymerization. In: Vanherle G, Smith DC, editors. International symposium on posterior composite resin dental restorative materials. Amsterdam: Peter Szulc Publishing Company; 1985. p. 109-37.

23- Torstenson B, Brannstrom M. Contraction gap under composite resin restorations: effect of hygroscopic expansion and thermal stress. Oper Dent. 1988;13(1):24-31.

24- Uno S, Asmussen E. Marginal adaptation of a restorative resin polymerized at reduced rate. Scand J Dent Res. 1991;99(5):440-4.

25- Versluis A, Tantbirojn D, Douglas WH. Distribution of transient properties during polymerization of a light-initiated restorative composite. Dent Mater. 2004;20(6):543-53.

26- Witzel MF, Calheiros FC, Gonçalves F, Kawano Y, Braga RR. Influence of photoactivation method on conversion, mechanical properties, degradation in ethanol and contraction stress of resinbased materials. J Dent. 2005;33(9):773-9.

27- Yap AU, Ng SC, Siow KS. Soft-start polymerization: influence on effectiveness of cure and post-gel shrinkage. Oper Dent. $2001 ; 26(3): 260-6$. 